\title{
PERFORMANCE OF RUBBLE MOUND BREAKWATERS UNDER TSUNAMI ATTACK, A CASE STUDY: HAYDARPASA PORT, ISTANBUL, TURKEY
}

\author{
Hasan Gokhan Guler ${ }^{1, *}$, Taro Arikawa ${ }^{2}$, Takayuki Oei ${ }^{2}$, Ahmet Cevdet Yalciner ${ }^{1}$ \\ ${ }^{1}$ Middle East Technical University, Department of Civil Engineering, Ocean Engineering Research Center, \\ Ankara, Turkey \\ ${ }^{2}$ Port and Airport Research Institute (PARI), Yokosuka, Kanagawa, Japan \\ *Corresponding Author, goguler@metu.edu.tr
}

\begin{abstract}
Ports are one of the most vulnerable coastal utilities in case of marine natural hazards such as tsunamis, and need to be protected against their devastating effects. Thus, studying the effects of tsunamis on protective structures such as breakwaters is critical. The Sea of Marmara is a part of an active earthquake zone that has generated tsunamis in the history. In terms of population density, coastal utilization, and economic potential, Marmara coastline seems most vulnerable to marine hazards. The availability of natural stones allows for wide use of rubble mound breakwaters as coastal protective structures in Turkey. The stability of these types of structures under the attack of storm waves has already been studied. However, their stability and performance under the effect of long waves and tsunami attacks have not yet been studied experimentally. The present study is a case study focusing on Haydarpasa Port, located at the southern entrance of Istanbul Bosphorus Strait (North coast of the Sea of Marmara). It aims to investigate the performance level of the port in case of tsunami attack.
\end{abstract}

Physical model experiments were conducted in the $105 \mathrm{~m}$ long wave flume in the Port and Airport Research Institute (PARI), Japan, with a Froude type length scale of 1/30. The experiments conducted to test the stability of rubble mound breakwater were twofold: i) solitary wave experiments, and ii) tsunami overflow experiments. The heights of incoming tsunami waves were selected from results of simulations were conducted in the same region (Oyo, 2007; Ayca, 2012; Yalciner et al., 2014; Guler et al., 2014; Aytore, 2015). First, the incoming solitary wave heights were selected as $5,7.5$ and $10 \mathrm{~cm}$. Using the overflow heights obtained from solitary wave experiments, i.e. wave height at the top of crown wall when the solitary waves are overtopping the crown wall, tsunami overflow experiments were conducted ranging from an overflow height of $1.1 \mathrm{~cm}$ to $4.6 \mathrm{~cm}$. Results of these experiments showed that Haydarpasa Breakwater, especially the crown wall of the breakwater, is not stable under a 
moderate tsunami attack. Therefore, an improved cross-section was also tested under the same conditions, and the improvement proved successful.

Keywords: Rubble mound breakwaters, tsunami attack, solitary wave, tsunami overflow experiments 


\section{INTRODUCTION}

Ports are the main infrastructures which should continue to function properly after any disasters. Because of their economic and social importance, the performance of the ports must be assessed under the effect of natural hazards. The Marmara sea coastline is the most vulnerable region in Turkey, considering its population density and economical potential. It is located at the western part of the North Anatolian Fault (NAF) zone in Turkey, which has experienced so many earthquakes and tsunamis throughout the history. Studies concluded that 35 tsunamis have occurred in this region in the past two millenniums, not only generated by earthquakes but also generated by landslides (Yalciner et al., 2002; Altinok et al., 2011).

Haydarpasa Port located in the southern entrance of the Istanbul Bosphorus Strait in the Sea of Marmara (Figure 1) was selected as the subject of the case study, which intends to investigate its performance under tsunami attack. This port is one of the most important ports in Turkey, serving both public and commercial activities of millions of people for passenger transfer between Europe and Asia and also carrying out cargo handling operations for megacity Istanbul. It has critical components such as the main railway station at the Asian Side of Istanbul, passenger terminals, cargo and container stock areas and ro-ro handling operations. The railway station itself is a historical building which has architectural importance.

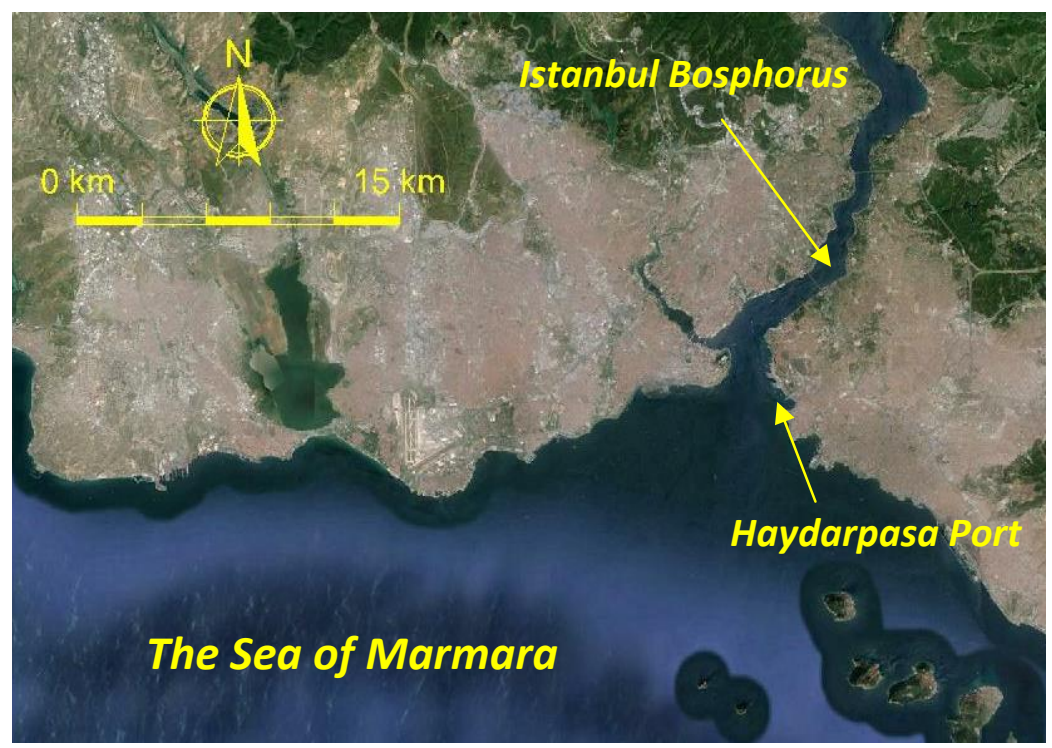

(a) General View of The Sea of Marmara 


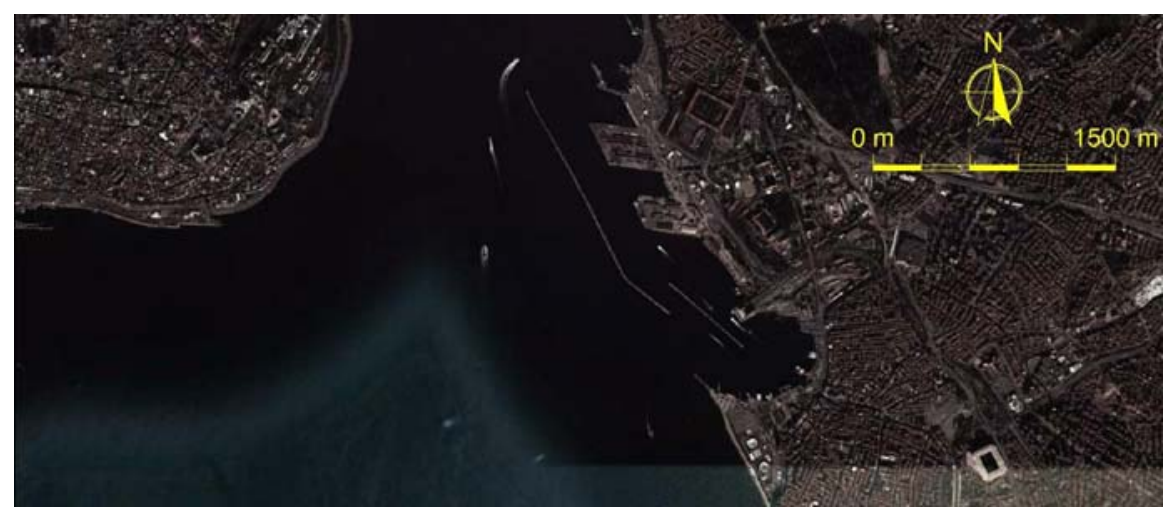

(b) Haydarpasa Port

Figure 1: The Location of the Haydarpasa Port

In this study, performance of the breakwaters of Haydarpasa Port -Haydarpasa Breakwaters, hereafterwere tested by physical model experiments. Haydarpasa Breakwaters are off-shore rubble mound breakwaters, including crown wall units, and have a length of approximately 3000 meters in total. The longer off-shore rubble mound breakwater, i.e. the breakwater at the western side in Figure $1 b$, was selected for the physical model experiments. Tests were conducted in two parts: i) solitary wave experiments and ii) tsunami overflow tests, in Port and Airport Research Institute (PARI), Japan. Solitary wave experiments were performed to understand the effect of the tsunami-like waves and to find the related tsunami overflow heights. It was concluded by Madsen et al.(2008) that the solitary waves are not capable of expressing the impact of tsunami attacks. As stated in Arikawa et al. (2012), stability of breakwaters depends on the period of time elapsed during tsunami overflow, due to water level difference between the sea side and harbour side of breakwaters. For this reason, a continuous flow over the cross-section is used to effectively understand effect of elapsed duration during tsunami attack referred as tsunami overflow experiments in this study in addition to the solitary wave experiments to understand the acting mechanism of the tsunamis on the selected coastal structure.

Physical model experiments showed that current cross-section of the Haydarpasa Breakwater is not stable under a possible tsunami attack in the Sea of Marmara. Therefore, a counter measure crosssection was proposed and tested. It was shown by physical experiments that the Haydarpasa Breakwater will be stable if its armour layer width at the harbour side of the breakwater is doubled. 


\section{EXPERIMENTAL SETUP}

\subsection{Scaling of Breakwater Cross-Section}

In this study, Froude Law is used as the scaling law since inertial and gravitational forces are dominant in wave motion and in wave effects on coastal structures. Stability of armour units can be modelled correctly if the stability numbers given by Equation 1 in both prototype and the model are the same (Hydralab, 2007). This condition can be satisfied when the weight scale $\left(\lambda_{w}\right)$ is computed using Equation 2.

$N_{s}=\frac{H_{s}}{\Delta D_{n 50}}$

$\lambda_{w}=\left(\lambda_{L}^{3}\right) \frac{\left(\gamma_{r}\right)_{m}}{\left(\gamma_{r}\right)_{p}}\left[\frac{\left(\gamma_{r}\right)_{p} /\left(\gamma_{w}\right)_{p}-1}{\left(\gamma_{r}\right)_{m} /\left(\gamma_{w}\right)_{m}-1}\right]^{3}$

In Equation 1, $H_{s}$ is defined as significant wave height $(m), \Delta$ is relative mass density and $D_{n 50}$ is nominal diameter of armour stone units. Following Equation $1,\left(\gamma_{r}\right)_{m}$ and $\left(\gamma_{r}\right)_{p}$ are unit weights of stones that are used in model and prototype which are taken as $2.65 \mathrm{t} / \mathrm{m}^{3}$ and $2.7 \mathrm{t} / \mathrm{m}^{3}$, respectively, in Equation 2 . Furthermore, $\left(\gamma_{w}\right)_{m}$ is the unit weight of water that is used in the model and $\left(\gamma_{w}\right)_{p}$ is the unit weight of sea water in the prototype. In the experiments, the unit weight of water was taken as $1.0 \mathrm{t} / \mathrm{m}^{3}$ whereas the unit weight sea water was assumed as $1.025 \mathrm{t} / \mathrm{m}^{3}$.

Length scale of the physical model was selected as 1:30 due to the limitations in wave channel dimensions and wave generator. Length, time, pressure and weight scales are given in Table 1.

Table 1: Model Scales

\begin{tabular}{|c|c|}
\hline Length & $\lambda_{L}=1: 30$ \\
\hline Time & $\lambda_{t}=1: 5.477$ \\
\hline Pressure & $\lambda_{p}=1: 30.75$ \\
\hline Weight & $\lambda_{w}=3.53 * 10^{-5}$ \\
\hline
\end{tabular}

Original cross-section of Haydarpasa Breakwater (Figure 2) was scaled (Figure 3) according to the model scales. Scaled stone weights are presented in Table 2. Note that the filter and the core layers of the breakwater was also scaled using the same weight scale obtained for the armour layers. 
Table 2: Weight of Stones

\begin{tabular}{|c|c|c|}
\hline Layer & Original Weight of Stones & Scaled Weight of Stones \\
\hline Armour Layer (Sea Side) & 3 tons & $100-150$ grams \\
\hline Filter Layer & $0.2-3$ tons & $50-100$ grams \\
\hline Core Layer & $0-0.2$ tons & $0-10$ grams \\
\hline Armour Layer (Harbour Side) & 1.5 tons & $50-100$ grams \\
\hline
\end{tabular}

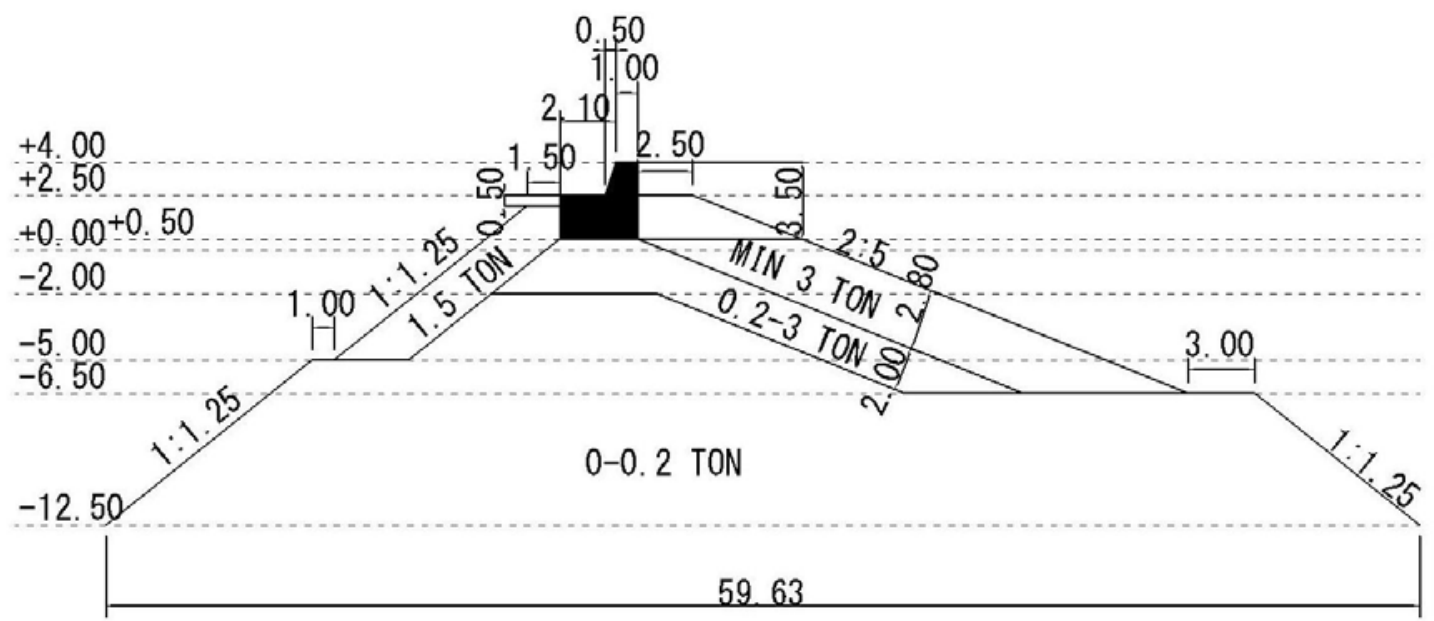

Figure 2: Original Cross-Section (Dimensions are in meters and figure is not to scale)

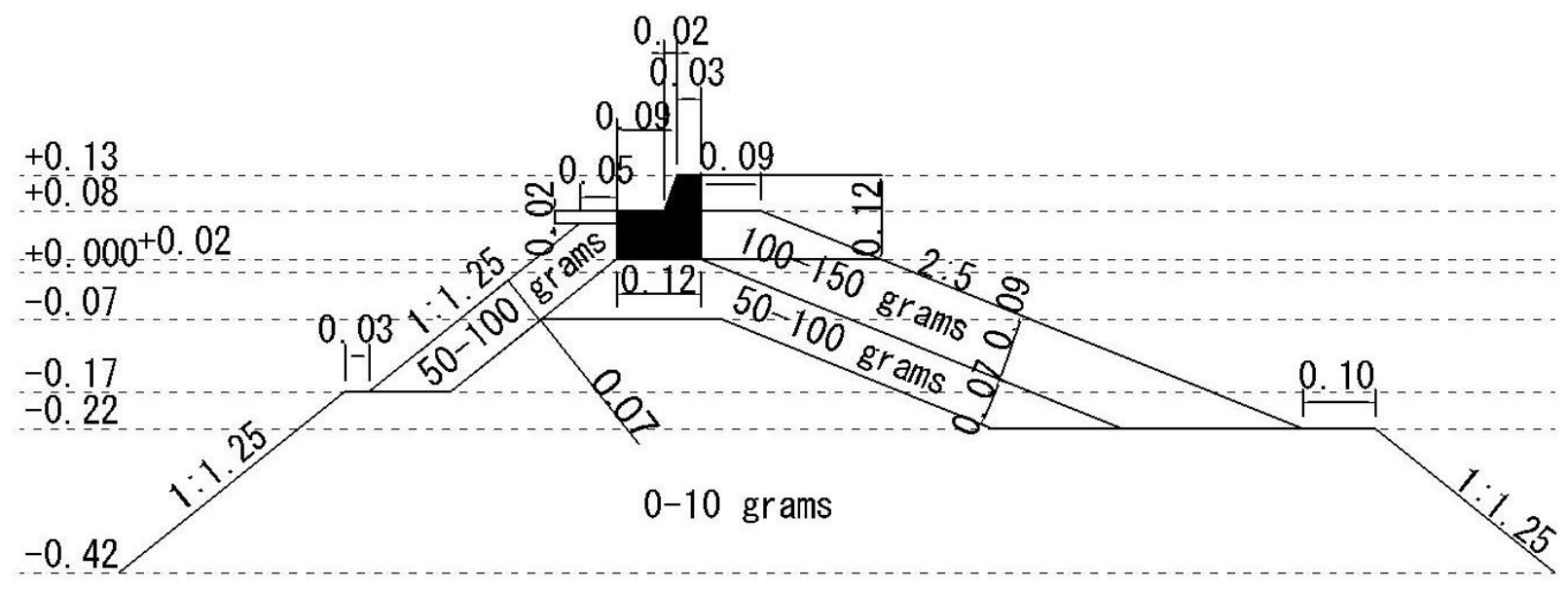

Figure 3: Scaled Cross-Section (Dimensions are in meters and figure is not to scale)

\subsection{Overview of the Wave Channel and Experimental Setup}

Physical model experiments were conducted in $105 \mathrm{~m}$ Wave Channel of PARI. Channel dimensions are $105 \mathrm{~m} \times 3.0 \mathrm{~m} \times 2.5 \mathrm{~m}$ with a smaller channel divided along this channel with dimensions $105 \mathrm{~m} \times 0.78 \mathrm{~m} \times 2.5 \mathrm{~m}$. 
Tests were conducted in the smaller channel. There are two sloped parts in this smaller channel where the slopes are $1 / 100$ and1/10. Furthermore, there is a flat part following the sloped parts, where the cross-section was built. In the experiments, nine water level (wave) gauges (WG1 to WG9) and four velocity meters (V1 to V4)were used, and experiments were recorded with three cameras. Experimental setup and measurement devices are given in Figures4a and $4 \mathrm{~b}$.

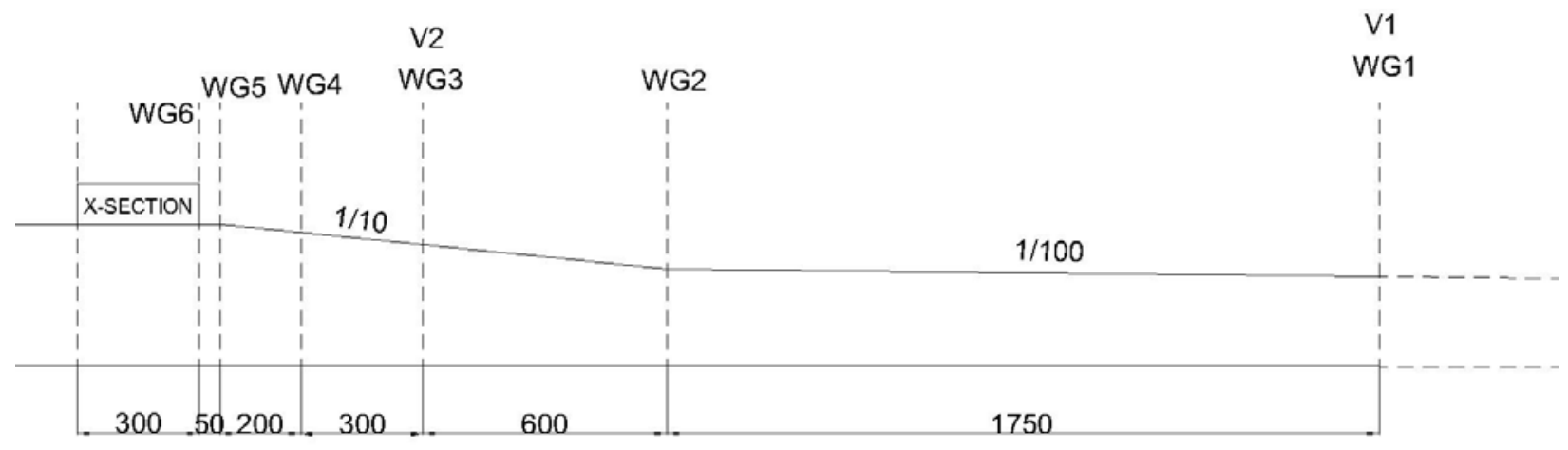

Figure 4a: Experimental Setup (Side View)

(All dimensions are in centimeters and figure is not to scale.)

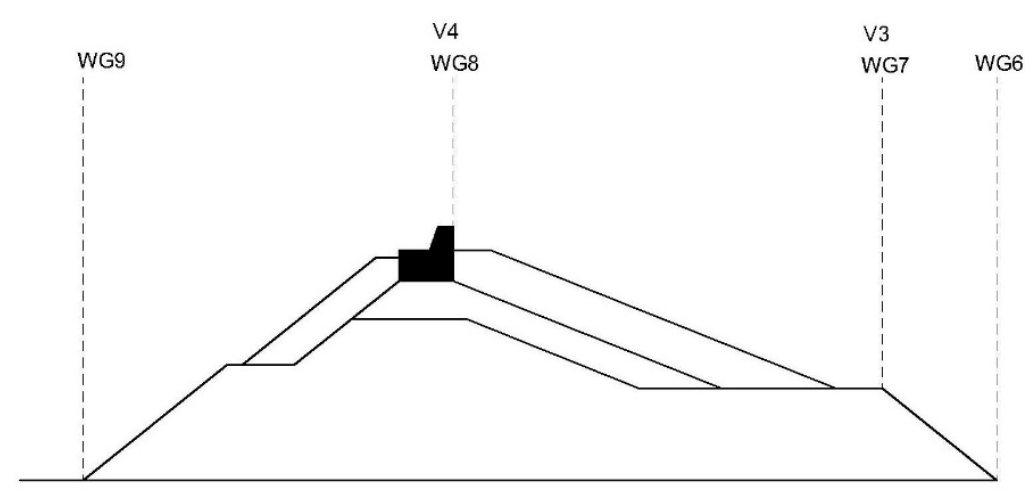

Figure 4b:Measurement Devices on the Cross-Section (Side View)

(Figure is not to scale.)

Crown wall units of Haydarpasa Breakwater were constructed in four pieces, and nine pressure gauges are placed on one of the pieces of crown wall units in the middle as shown in Figure 5. Pressure gauges are denoted as UG1 to UG9. 


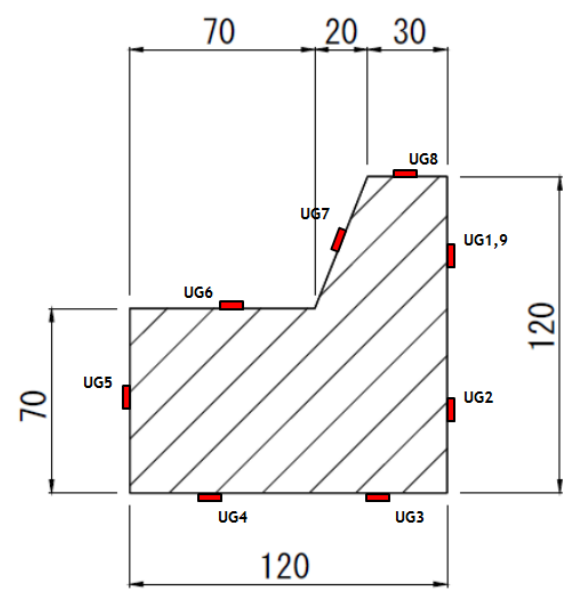

Figure 5: Placement of Pressure Gauges (UG1 to UG9) onto Crown Wall Unit (Dimensions are in millimeters and figure is not to scale.)

\subsection{Solitary Wave Generation for Stability Experiments and Pumping System for Tsunami Overflow Experiments}

In the first stage of the experiments, the solitary waves were generated by piston-type wave generator. Different heights of solitary waves were generated in the experiments. Tsunami overflow caused damage due to the difference in acting forces originating from water level differences between the harbour and the sea sides of the breakwater. In order to generate constant level overflow on the breakwater, a pump was used to increase water level up to a constant height at the sea side of the breakwater. This overflow height was kept constant during the experiments by the use of the circulating pump at the harbour side. The experiment continued until the damage occurs at the cross-section, which also reveals duration of tsunami overflow (with respect to the tsunami period) necessary for the damage to occur.

\section{PHYSICAL MODEL EXPERIMENTS}

Previous stability experiments on rubble mound breakwaters show that, there are different damage and failure modes of rubble mound structures. Armour layers of rubble mound structures consisting of large rocks are usually designed to resist extreme storm conditions and be stable under usual wind wave conditions. Design storms and other extreme events such as tsunamis and storm surges may cause damages in these layers. Armour layer damage can be observed as displacement of stones or erosion of the profile. On the other hand, rubble mound structures can fail due to tsunamis, storm surges or high wind wave conditions by sliding or overturning of crown wall units or scouring in the armour layer of the rubble mound structure at the harbour side. In this study, it is observed that the main failure mechanism 
of Haydarpasa Breakwater is sliding of crownwall units. Sliding of crownwall units is due to the difference in the resisting and the driving forces. When the driving forces, i.e. direct wave pressure and uplift pressure forces, are greater than the resisting forces, i.e. support reactions and weight of the crown wall, crown wall units slide.

Physical model experiments were carried out in two parts: i) solitary wave experiments and ii) tsunami overflow experiments. Damage and failure modes of Haydarpasa Breakwater were investigated by these physical model experiments. Damage definition and selected experiments are also presented in this part.

\subsection{Damage Assessment Methodology and Damage Definition}

The most commonly used damage parameter (S) proposed by Broderick (1984) is given by Equation 2 relating the eroded area in the profile $(A)$ and nominal diameter of armour stones $\left(D_{n 50}\right)$ to damage parameter (S). Nominal diameter is defined as the cube root of the median stone weight over stone unit weight ratio. This parameter is used in common rubble mound breakwater design formulas (Van der Meer, 1988; Vidal et al., 2006; Etemad-Shahidi and Bonakdar, 2009; Etemad-Shaidi and Bali, 2011)

$S=\frac{A}{D_{n 50}^{2}}$

Qualitative interpretation of Sin order to understand level of the damage is given in Table 3. The values given in Table 3 are usually used to define damage levels for different rubble mound breakwater face slopes.

Table 3: Damage Levels (adopted from CIRIA et al., 2007)

\begin{tabular}{|c|c|c|c|}
\hline \multirow{2}{*}{$\begin{array}{c}\text { Slope } \\
(\cot \alpha)\end{array}$} & \multicolumn{3}{|c|}{ Damage Level (S) } \\
\cline { 2 - 4 } & Start of Damage & Intermediate Damage & Failure \\
\hline 1.5 & 2 & $3-5$ & 8 \\
\hline 2 & 2 & $4-6$ & 8 \\
\hline 3 & 2 & $6-9$ & 12 \\
\hline 4 & 3 & $8-12$ & 17 \\
\hline
\end{tabular}


In addition to evaluation of damage parameter (S) and corresponding qualitative damage level, sliding of the crown wall units are given for all of the test cases at three levels: "No Sliding", "Small Sliding" and "Sliding".

There are various methodologies for assessment of the damage to rubble mound structures. Van der Meer (1988) summarized and Vidal et al. (2003) comparatively studied these methodologies used for damage assessment given in Table 4.

Table 4:Damage Assessment Methodologies (Van der Meer (1988) and Vidal et al. (2003))

\begin{tabular}{|l|l|}
\hline Researcher & Damage Assessment Methodology \\
\hline Hudson (1959) & $\begin{array}{l}\text { Measured damage with a rod equipped with a circular foot with a } \\
\text { diameter equal to one-half the average diameter of the armour } \\
\text { stones. }\end{array}$ \\
\hline Hedar (1960) & Counted the number of stones displaced. \\
\hline $\begin{array}{l}\text { Ahrens (1975) } \\
\text { Thompson and Shuttler (1975) } \\
\text { Broderick (1984) }\end{array}$ & Used the same methodology with Hudson (1959). \\
\hline Vidal et al. (2003) & Counting the extracted stones forming extra layers over the armour \\
\hline Vidal et al. (2003) & $\begin{array}{l}\text { Counting the number of pixels of the areas colored with the color of the } \\
\text { inner layer of the armour. Note that this methodology is only valid if } \\
\text { damage is limited to armour layer. }\end{array}$ \\
\hline
\end{tabular}

In this study, the vertical profile of the cross-section was measured before and after each set of experiment to estimate the damage to the armour layer. Vertical profiles were measured with $5 \mathrm{~cm}$ intervals starting from 0 to $80 \mathrm{~cm}$ at the sea side for solitary wave tests and with $5 \mathrm{~cm}$ intervals starting from -15 to $-40 \mathrm{~cm}$ at the harbour side for both solitary wave and tsunami overflow tests. Reference point of measurements, Point 0 , was selected as the boundary of the crown wall at the right hand side, indicated by an arrow in Figure 6. Profile measurements were made along three lines. These three lines were chosen along the width of the cross-section at 18, 41 and $60 \mathrm{~cm}$ away from the glass boundary, which is seen in all snapshots of experiments. The maximum of damage parameters along these lines were regarded as damage of the cross-section. 


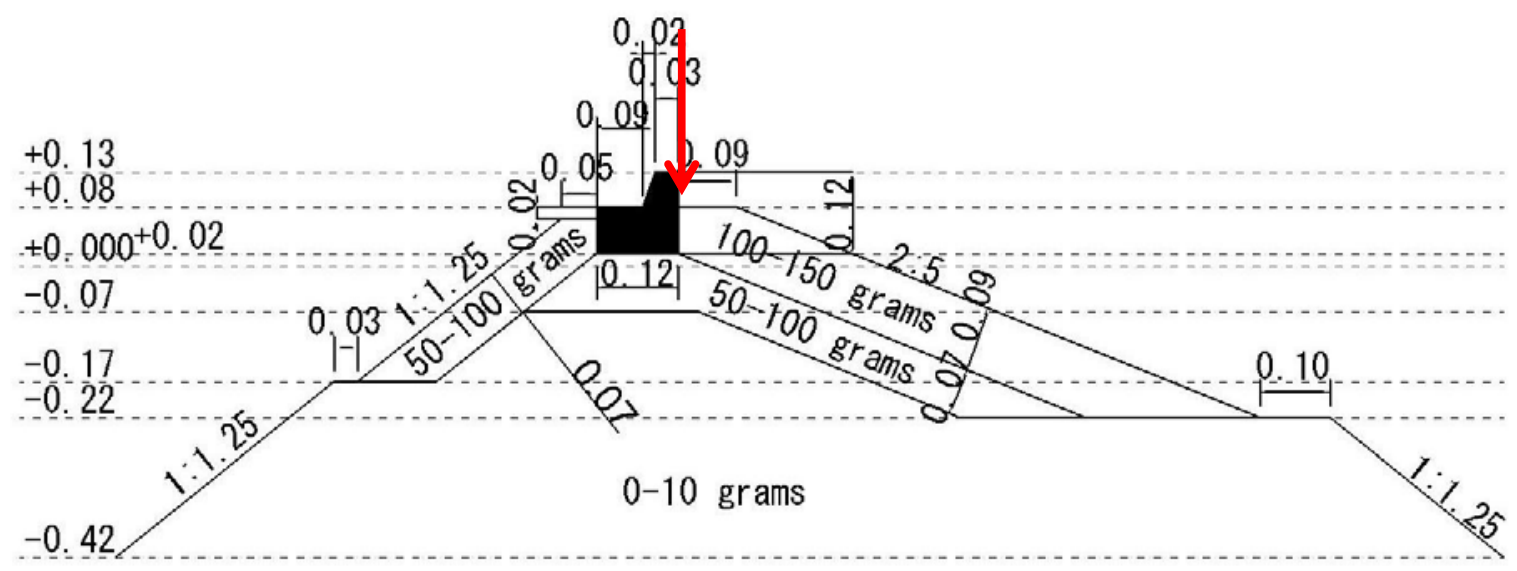

Figure 6: Reference Point for Profile Measurements (Point 0)

(Figure is in model dimensions and not to scale.)

\subsection{Solitary Wave Experiments}

Tsunami generation, propagation and inundation characteristics are usually determined with tsunami modelling codes. Different earthquake sources around the target region are simulated; thus, possible tsunami characteristics can be determined. According to the preliminary results of numerical modelling studies conducted by hybrid tsunami simulation codes, NAMIDANCE (2D depth averaged shallow water model with dispersion) and STOC-CADMAS System (Quasi 3D in large domains and 3D in small domains), a three meter tsunami height is expected in Haydarpasa Region (Oyo, 2007; Ayca, 2012; Yalciner et al., 2014; Guler et al., 2014; Aytore, 2015). On the other hand, the 2011 Great East Japan Tsunami taught that earthquake parameters used as sources of tsunamis may not be sufficient all the time. Therefore, even if the numerical model studies anticipate a tsunami height less than three meters, it is still really important to investigate the performance of this breakwater.

Based on the results of the preliminary tsunami simulation studies in the Sea of Marmara, solitary waves with the heights of $5 \mathrm{~cm}, 7.5 \mathrm{~cm}$, and $10 \mathrm{~cm}$ in model scale -corresponding to $1.5 \mathrm{~m}, 2.25 \mathrm{~m}$ and $3 \mathrm{~m}$ in prototype scale- were used in the physical model experiments. For each solitary wave experiment, the duration of measurement was taken as 3 minutes and the sampling interval of measurements was set as $200 \mathrm{~Hz}$.

Results of solitary wave experiments are given in Table 5 .Solitarywave experiment with $\mathrm{H=10} \mathrm{cm}$ is selected and presented in detail as a part of Section 3.2 below. 
Table 5: Results of Solitary Wave Experiments

\begin{tabular}{|c|c|c|c|c|c|c|}
\hline & \multicolumn{2}{|r|}{ Sea Side } & \multicolumn{2}{|c|}{ Harbour Side } & \multirow{2}{*}{$\begin{array}{c}\text { Sliding } \\
\text { Condition }\end{array}$} & \multirow{2}{*}{$\begin{array}{c}\text { Overflow } \\
\text { Height }(\mathrm{cm})\end{array}$} \\
\hline $\mathrm{H}(\mathrm{cm})$ & $\mathbf{S}$ & Damage Level & $\mathbf{S}$ & Damage Level & & \\
\hline 5 & - & No Damage & - & No Damage & No Sliding & - \\
\hline 7.5 & 3.27 & Initiation of Damage & 0.28 & No Damage & No Sliding & 1.7 \\
\hline 10 & 8.33 & Failure & 9.30 & Failure & Sliding & 4.6 \\
\hline
\end{tabular}

\section{Solitary Wave Experiment with $\mathrm{H}=10 \mathrm{~cm}$}

A $10 \mathrm{~cm}$ height ( $3 \mathrm{~m}$ in prototype) solitary wave was used to test the cross-section in this case. Under the action of this wave, overflow occurred, and the crown wall units were slid because of the pressure applied on the crown wall units mainly caused by the water level difference between two sides of the breakwater. The harbour side of the cross-section totally failed, and the stones at the upper side of the sea side of the cross-section were washed away with the crown wall units.

Figure 7 presents a snapshot from the test, showing the cross-sectional view of the solitary wave action and still water level (SWL). The overflow height was measured as $4.6 \mathrm{~cm}$ in this test.

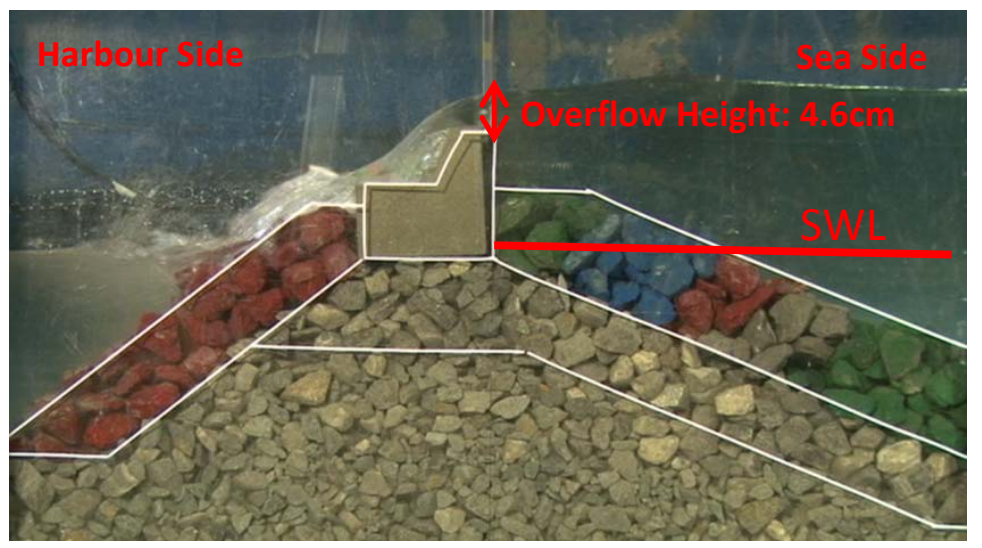

Figure 7:Solitary Wave Action( $\mathrm{H}=10 \mathrm{~cm}$ in model scale)

Figures 8 and 9 present the cross-sectional views of sliding of the crown wall units, and movement of the stones at the sea side, respectively. 


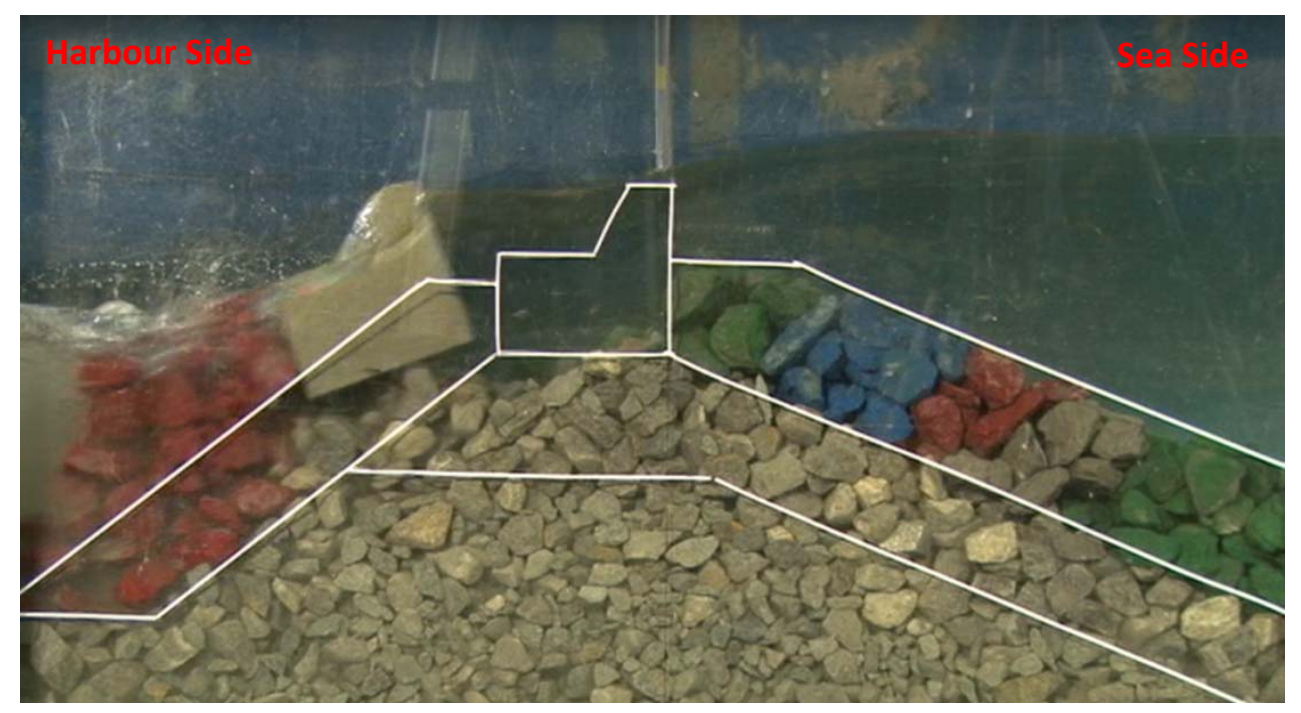

Figure 8: Sliding of Crown Wall Units

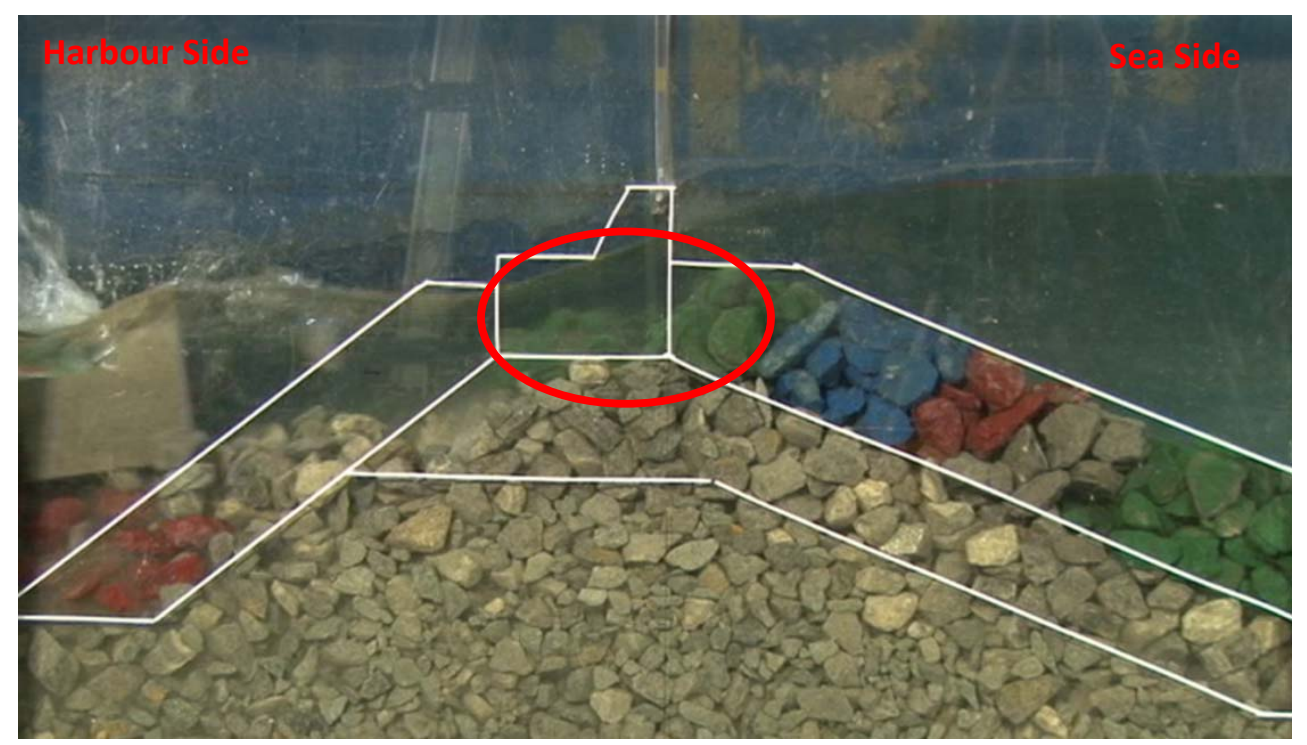

Figure 9: Movement of the Stones at the Upper Layer of the Sea Side of the Cross- Section

On the other hand, as can be seen in Figure 10, stones in the lower layers of the cross-section at the sea side did not move. 


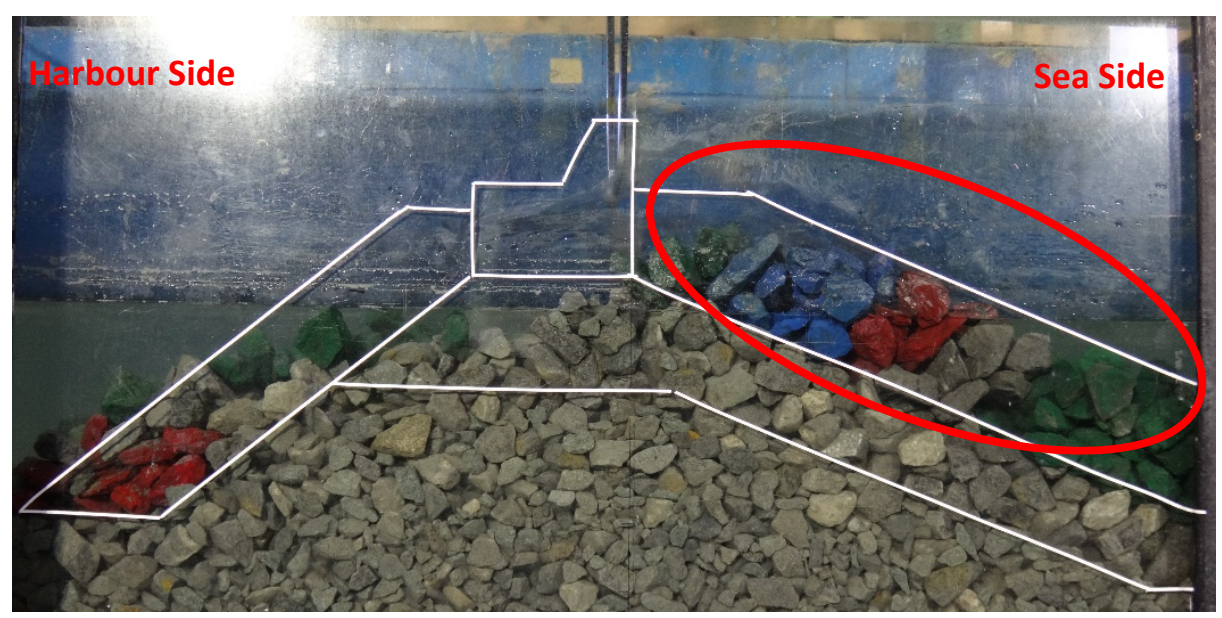

Figure 10: Position of Lower Layer at the Sea Side

\subsection{Tsunami Overflow Experiments}

Tsunami overflow experiments were conducted to investigate the time effect of overflow. These experiments were firstly planned to test the cross-section under the effect of tsunami overflow height ranging between 1.1 and $4.6 \mathrm{~cm}$ in model scale corresponding to 33 and $138 \mathrm{cmin}$ prototype scale, respectively, since the overflow height was measured as $1.7 \mathrm{~cm}$ for solitary wave with $\mathrm{H}=7.5 \mathrm{~cm}$ and 4.6 $\mathrm{cm}$ for solitary wave with $\mathrm{H}=10 \mathrm{~cm}$. However, the experiments showed that the current cross-section of Haydarpasa Breakwater, original cross-section hereafter, is not stable around the overflow height of 1.8 $\mathrm{cm}$ in model scale. Therefore, a counter measure cross-section, improved cross-section hereafter, doubling the armour layer width at the harbour side was proposed.

All experiments with the original and improved cross-section were conducted for 10 minutes and recorded for 13 minutes with a sampling interval of $200 \mathrm{~Hz}$.

\subsubsection{Original Cross-Section}

Tsunami overflow experiments on original cross-section were conducted within an overflow height range of $1.1 \mathrm{~cm}-1.95 \mathrm{~cm}$. Table 6 displays the results of these experiments as well as the sliding condition of the crown walls and the failure time.

Table 6: Results of Tsunami Overflow Experiments on Original Cross-Section

\begin{tabular}{|c|c|c|c|c|c|}
\hline$\#$ & $\mathbf{h}^{*}(\mathbf{c m})$ & $\mathbf{S}$ & Damage Level & Sliding Condition & Failure Time** $^{* *}$ \\
\hline $\mathbf{1}$ & 1.1 & - & No Damage & No Sliding & - \\
\hline $\mathbf{2}$ & 1.15 & - & No Damage & No Sliding & - \\
\hline $\mathbf{3}$ & 1.2 & - & No Damage & No Sliding & - \\
\hline $\mathbf{4}$ & 1.3 & - & No Damage & No Sliding & - \\
\hline
\end{tabular}




\begin{tabular}{|c|c|c|c|c|c|}
\hline $\mathbf{5}$ & 1.4 & 1.36 & No Damage & Small Sliding & - \\
\hline $\mathbf{6}$ & 1.7 & 8.37 & Failure & Sliding & 2 mins \\
\hline $\mathbf{7}$ & 1.85 & 1.73 & No Damage & Small Sliding & - \\
\hline $\mathbf{8}$ & 1.9 & 10.24 & Failure & Sliding & 6.5 mins \\
\hline $\mathbf{9}$ & 1.95 & 10.63 & Failure & Sliding & 2 mins 10 secs \\
\hline * Overflow height is given in model scale. \\
** Failure time is given in terms of recording time. \\
\hline
\end{tabular}

The results in Table 6 show that damage level and sliding condition may not follow the general trend in some tests such as Test 7, i.e. Test 7 resulted in 'no damage' and 'small sliding' whereas Test 6 resulted in 'failure' and 'sliding' even if the overflow height of Test 7 is greater. This result and similar ones that are obtained in further tests are discussed in Section 4 in details; however, it should be noted that placement and orientation of stones are the main reasons for these results.

Tsunami overflow experiments on original cross-section with an overflow height of $\mathrm{h}=1.4 \mathrm{~cm}$ and $\mathrm{h}=1.95$ $\mathrm{cm}$ are selected to be presented in details.

\section{Tsunami Overflow Experiment with $h=1.4 \mathrm{~cm}$ height of overflow in model scale}

Tsunami overflow experiment with $\mathrm{h}=1.4 \mathrm{~cm}$ in model scale and $42 \mathrm{~cm}$ in prototype was conducted as Test 5. As can be seen in Figure 11, this case resulted in 'no damage', and approximately 1.4 cmsliding in model scale corresponding to 'small sliding'.

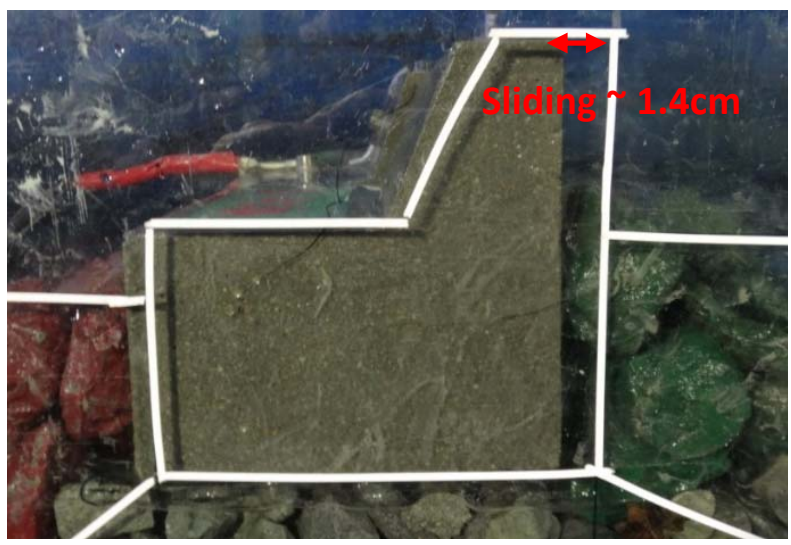

Figure 11:SmallSliding of Crown Wall Units

\section{Tsunami Overflow Experiment with $h=1.95 \mathrm{~cm}$ height of overflow in model scale}

An overflow height of $1.95 \mathrm{~cm}$ in model scale corresponding to $58.5 \mathrm{~cm}$ in prototype was applied to Haydarpasa Breakwater as in Test 9 for the original cross-section. This overflow height caused total damage to the cross-section. Crown wall units slid due to the water level difference between the sea side and the harbour side of the cross-section. The sliding did not occur simultaneously in this case. 
There was a time difference between the sliding of the individual crown wall unit as indicated in Figure 12.

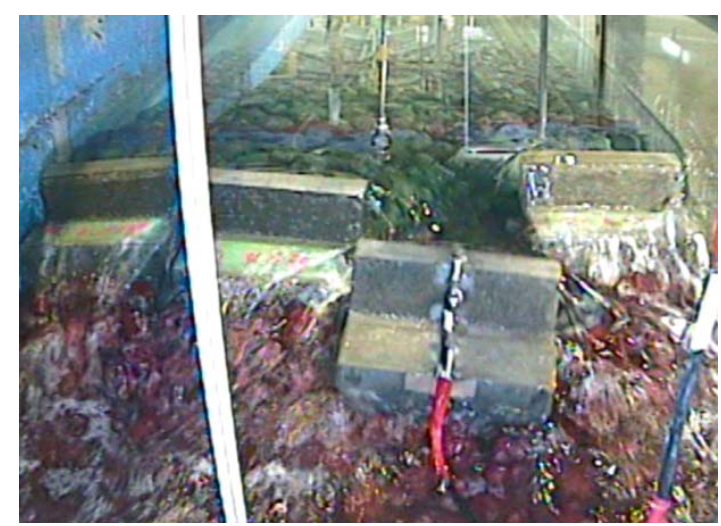

Figure 12: Time Difference in Sliding of Crown Wall Units

\subsubsection{Improved Cross-Section}

Tsunami overflow experiments on the original cross-section showed that it is not stable around a $1.7 \mathrm{~cm}$ overflow height in model scale corresponding to $54 \mathrm{~cm}$ overflow height in prototype scale. As stated previously, this overflow height corresponds to $7.5 \mathrm{~cm}$ solitary wave in model scale which is $2.25 \mathrm{~m}$ in prototype scale. Since a three meter height tsunami can be expected near Haydarpasa Breakwater, a counter measure cross-section was proposed and tested. This counter measure cross-section is an improved version of the original cross-section. The improvement made by doubling the width of the armour layer at the harbour side. The width of the armour layer is increased from $7 \mathrm{~cm}$ to $14 \mathrm{~cm}$ in model scale. The improved cross-section is given in Figure 13.

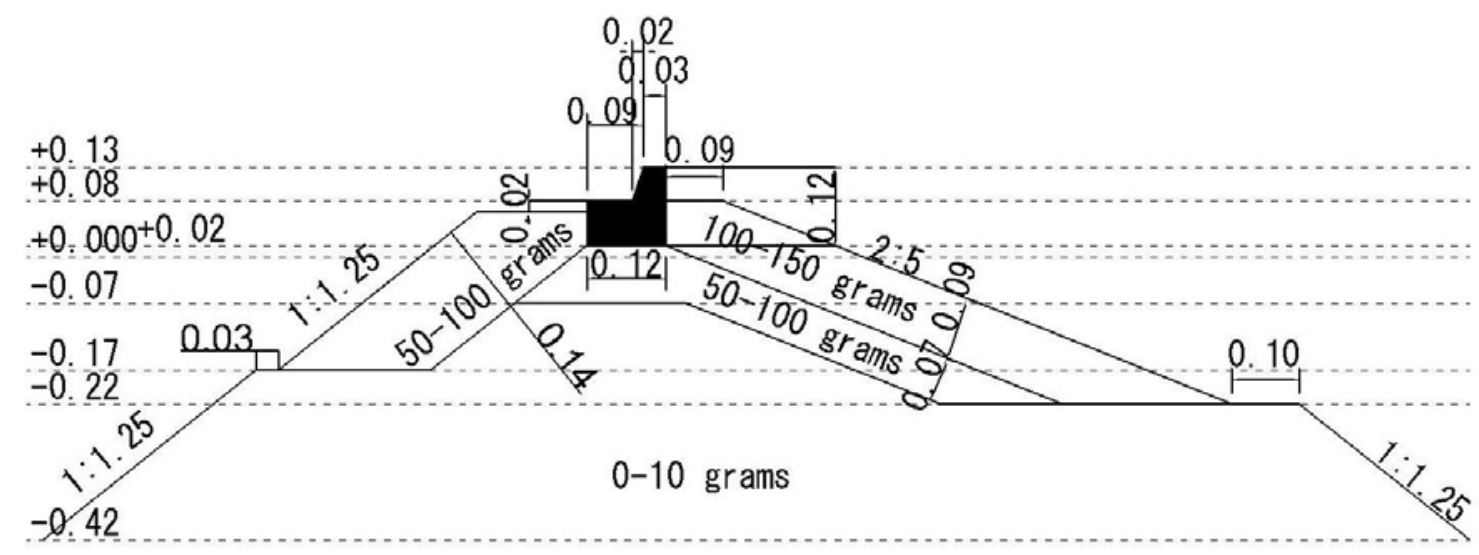

Figure 13: Improved Cross-Section (Dimensions are in meters and in model scale.) 
Tsunami overflow experiments on the improved cross-section were conducted using an overflow height ranging from $1.5 \mathrm{~cm}$ to $4.6 \mathrm{~cm}$ corresponding to the solitary wave heights in the range of $7.5 \mathrm{~cm}$ to 10 $\mathrm{cm}$ as presented in Table 7. Furthermore, details of two selected tsunami overflow experiments on the improved cross-section with an overflow of height of $h=4.4 \mathrm{~cm}$ and $\mathrm{h}=4.6 \mathrm{~cm}$ are presented below.

Table 7: Results of Tsunami Overflow Experiments on the Improved Cross-Section

\begin{tabular}{|c|c|c|c|c|c|}
\hline$\#$ & $\mathbf{h}^{*}(\mathbf{c m})$ & $\mathbf{S}$ & Damage Level & Sliding Condition & Failure Time** \\
\hline $\mathbf{1}$ & 1.5 & - & No Damage & No Sliding & - \\
\hline $\mathbf{2}$ & 1.6 & - & No Damage & No Sliding & - \\
\hline $\mathbf{3}$ & 2.1 & 6.23 & Intermediate Damage & No Sliding & - \\
\hline $\mathbf{4}$ & 2.7 & 4.66 & Intermediate Damage & No Sliding & - \\
\hline $\mathbf{5}$ & 2.8 & 6.42 & Intermediate Damage & No Sliding & - \\
\hline $\mathbf{6}$ & 3.4 & 5.98 & Intermediate Damage & Small Sliding & - \\
\hline $\mathbf{7}$ & 3.65 & 5.10 & Intermediate Damage & Small Sliding & - \\
\hline $\mathbf{8}$ & 4.3 & 6.07 & Intermediate Damage & Small Sliding & - \\
\hline $\mathbf{9}$ & 4.4 & 9.31 & Failure & Sliding & 2 mins 50 secs \\
\hline $\mathbf{1 0}$ & 4.6 & 18.88 & Failure & Sliding & 3 mins 53 secs \\
\hline * Overflow height is given in model scale. \\
** Failure time is given in terms of recording time. \\
\hline
\end{tabular}

\section{Tsunami Overflow Experiment with $h=4.4 \mathrm{~cm}$ height of overflow in model scale}

Overflow heighth=4.4 $\mathrm{cm}$ in model scale corresponding to $132 \mathrm{~cm}$ in prototype scale resulted in 'failure'. However, two out of four pieces of crown wall units slide in this experiment as presented in Figures 14a and 14b. Considering sliding of two crown wall units only, results of this test is different compared to the tests on the improved cross-section resulted in 'failure'. Since the crown wall units on the left hand side slide earlier than others, water level difference decreased, and they stayed stable.

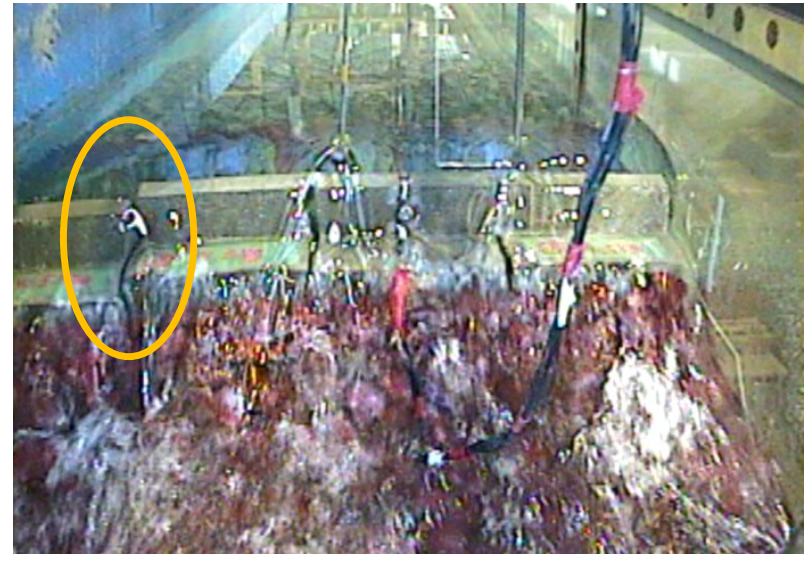

(a) - Sliding Instant

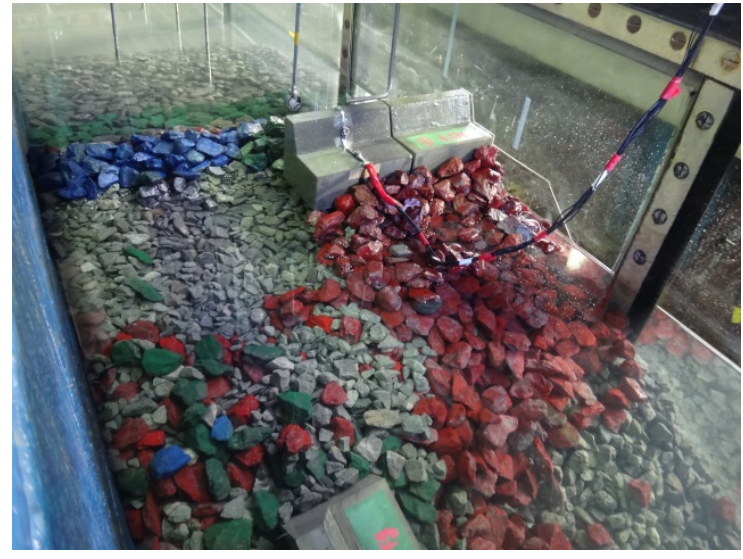

(b) - After sliding 
Figure 14: Sliding of Crown Wall Units at the Left Hand Side

\section{Tsunami Overflow Experiment with $h=4.6 \mathrm{~cm}$ height of overflow in model scale}

The final tsunami overflow experiment on the improved cross-section was that with an overflow height of $4.6 \mathrm{~cm}$ in model, which corresponds to $138 \mathrm{~cm}$ overflow height in prototype. This experiment resulted in failure of the cross-section. Figure 15 demonstrates the very moment of the crown wall units sliding and damage at the harbour side are given.

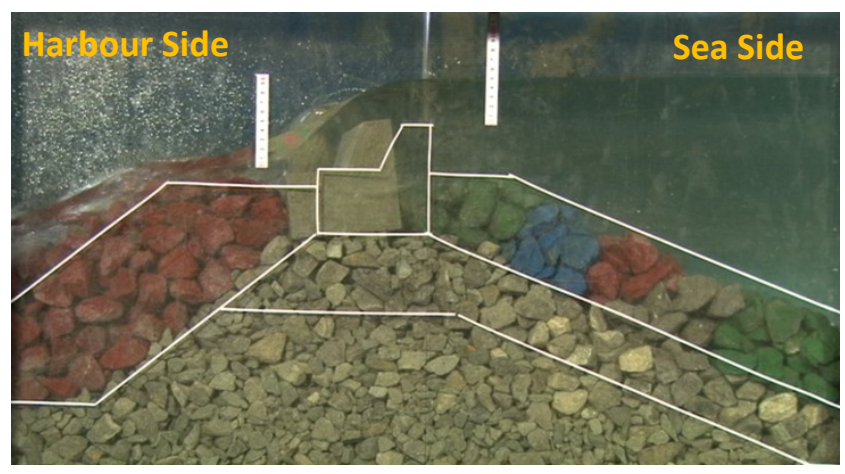

(a) - Sliding Instant

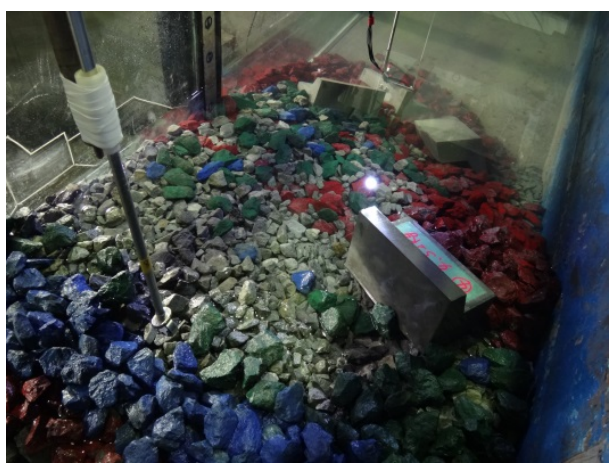

(b) - Damage atthe Harbour Side

Figure 15: Failure $(h=4.6 \mathrm{~cm}$ in model scale)

\subsection{Calculation of Supporting Forces Applied by the Armour Layer at the Harbour Side}

Forces acting on the crown wall units were assessed to understand the sliding mechanism and the effect of placement and orientation of stones for each total failure case of both the solitary wave and tsunami overflow experiments by analyzing pressure measurements and video recordings. Intermediate damage cases are not included into calculations since pressure measurements and video recordings do not suffice to observe 'intermediate damage' effectively. Pressure forces, weight of crown wall units, and supporting forces applied by the armour layer at the harbour side are the main forces acting on the crown wall units. Static friction coefficient is another parameter that directly affects the acting forces on the crown wall units.

Nine pressure measurement gauges were used at eight different locations to measure pressure distribution around one of the crown wall units. Using measured pressure values, pressure forces were 
calculated around the crown wall units. In Figure 16, the coordinate system used to describe the acting forces on the crown wall units, places of pressure measurement gauges, and acting direction of all type of forces are given.

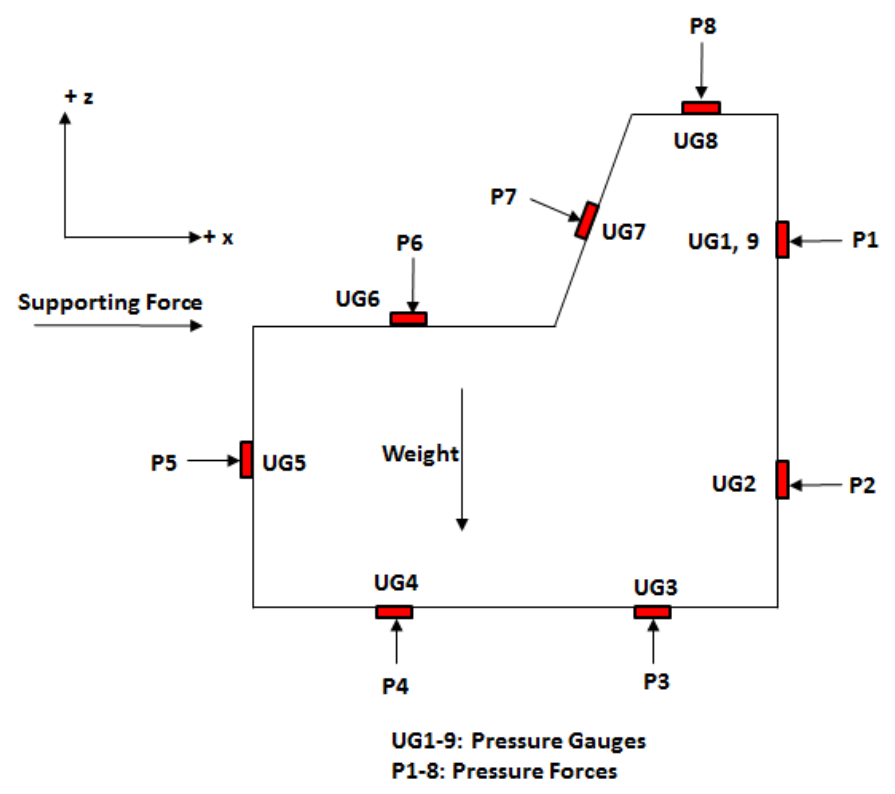

Figure 16:Locations of Pressure Gauges and All Forces Acting on the Crown Wall Units

The factor of safety against sliding (F. S.) is given by Equation 3, wherein $F_{x}$ is the total force acting in $\mathrm{x}$ direction, $F_{z}$ is the total force acting in z-direction, and $\mu$ is static friction coefficient. $F_{x}$ and $F_{z}$ are given by Equations 4 and 5, respectively.

F. S. $=\frac{\mu F_{z}}{F_{x}}$

$F_{x}=P 5+P 7_{x}-P 1-P 2$

$F_{z}=P 4+P 3-$ Weight $-P 6-P 8-P 7_{z}$

Pressure forces given by P1, P2, P3, P4, P5, P6, P7 ( $x$ and $z$ directions) and P8 were calculated by multiplying pressure measurements at the related locations by area of action. Since the length in $y$ direction was constant, pressure forces are given in $\mathrm{N} / \mathrm{m}$. Furthermore, the weight of crown wall units were measured and found as $249.6 \mathrm{~N} / \mathrm{m}$. On the other hand, the static friction coefficient $(\mu)$ was calculated by conducting experiments with no armour layer at the harbour side, i.e. the supporting force applied by the armour layer at the harbor side was zero for this test. In these experiments, the 
overflow height was $0.45 \mathrm{~cm}$. The factor of safety against sliding was assumed to be 1 just before sliding. Using pressure measurements at that instant and assuming factor of safety as 1 , i.e. F. S. $=1$, static friction coefficient was found as 0.45 .

Supporting forces were calculated in a similar way to pressure forces. It was assumed that the factor of safety just before sliding is 1 , which is the limiting condition. The calculated factor of safety values were lower than 1 , and obviously sliding was prevented by supporting forces. Therefore, supporting forces were calculated considering the difference between the limiting sliding condition, i.e. F.S. $=1$, and safety factor values previously calculated for each total failure case as given by Equation 6 . A sample calculation is given in Table 8 for the experiment conducted by an overflow height of $4.6 \mathrm{~cm}$ on the improved cross-section (Test 10 in Table 7).

$F_{x}=\mu F_{z}+$ Supporting Force

The results of supporting force calculations are presented in Table 9. Note that the experiment conducted on the improved cross-section with an overflow height of $4.4 \mathrm{~cm}$ is not included in Table 9 since the crown wall unit with measurement gauges did not slide.

Table 8: Sample Calculation of Supporting Force(Improved Cross-Section, $h=4.6 \mathrm{~cm}$ )

\begin{tabular}{|c|c|c|c|}
\hline Gauge Number & Pressure Measurement $\left(\mathrm{N} / \mathrm{m}^{2}\right)$ & Length of Action (m) & Pressure Force $(\mathrm{N} / \mathrm{m})$ \\
\hline 1 & 1494.317 & 0.060 & 89.659 \\
\hline 2 & 1478.760 & 0.060 & 88.726 \\
\hline 3 & 1372.198 & 0.060 & 82.332 \\
\hline 4 & 1357.277 & 0.060 & 81.437 \\
\hline 5 & -31.653 & 0.070 & -2.216 \\
\hline 6 & 294.812 & 0.070 & 20.637 \\
\hline 7 & 110.743 & 0.054 & 5.980 \\
\hline 8 & -413.881 & 0.030 & -12.416 \\
\hline Weight & - & - & 249.600 \\
\hline \multicolumn{4}{|l|}{ Results } \\
\hline \multicolumn{2}{|c|}{ Summation of Forces in negative $x$-direction $(\mathrm{N} / \mathrm{m})$} & \multicolumn{2}{|l|}{175.048} \\
\hline \multicolumn{2}{|c|}{ Summation of Forces in negative $z$-direction $(\mathrm{N} / \mathrm{m})$} & \multicolumn{2}{|l|}{96.273} \\
\hline \multicolumn{2}{|c|}{ Factor of Safety } & \multicolumn{2}{|l|}{0.248} \\
\hline \multicolumn{2}{|c|}{ Supporting Force in positive $x$-direction $(\mathrm{N} / \mathrm{m})$} & \multicolumn{2}{|l|}{131.725} \\
\hline
\end{tabular}


Table 9: Supporting Forces

\begin{tabular}{|c|c|c|c|}
\hline \multicolumn{4}{|l|}{ Original Cross-Section } \\
\hline Solitary Wave Height & Failure Time (sec) & F. S. Against Sliding & Supporting Force $(\mathrm{N} / \mathrm{m})$ \\
\hline 10 & - & 0.861 & 15.01 \\
\hline \multicolumn{4}{|l|}{ Original Cross-Section } \\
\hline Overflow Depth $(\mathrm{cm})$ & Failure Time (sec) & F. S. Against Sliding & Supporting Force $(\mathrm{N} / \mathrm{m})$ \\
\hline 1.7 & 120 & 0.949 & 4.20 \\
\hline 1.9 & 394 & 0.884 & 9.06 \\
\hline 1.95 & 130 & 0.937 & 4.85 \\
\hline \multicolumn{4}{|l|}{ Improved Cross-Section } \\
\hline Overflow Depth (cm) & Failure Time (sec) & F. S. Against Sliding & Supporting Force $(\mathrm{N} / \mathrm{m})$ \\
\hline 4.6 & 233 & 0.248 & 131.73 \\
\hline
\end{tabular}

\section{COMPARISON AND DISCUSSION OF THE RESULTS}

In Section 4, the results of measurements and observations from the experiments with both solitary wave and tsunami overflow experiments are compared and discussed in terms of failure mechanism and acting forces, and stability of the armour layer at the sea and the harbour side. Furthermore, the performance of the improved cross-section is evaluated.

\subsection{Failure Mechanism and Acting Forces}

Both type of experiments showed that the main failure mechanism of Haydarpasa Breakwater is sliding of the crown wall units. Sliding occurs due to the water level difference between the sea side and the harbour side of the cross-section as shown in Figure 17.

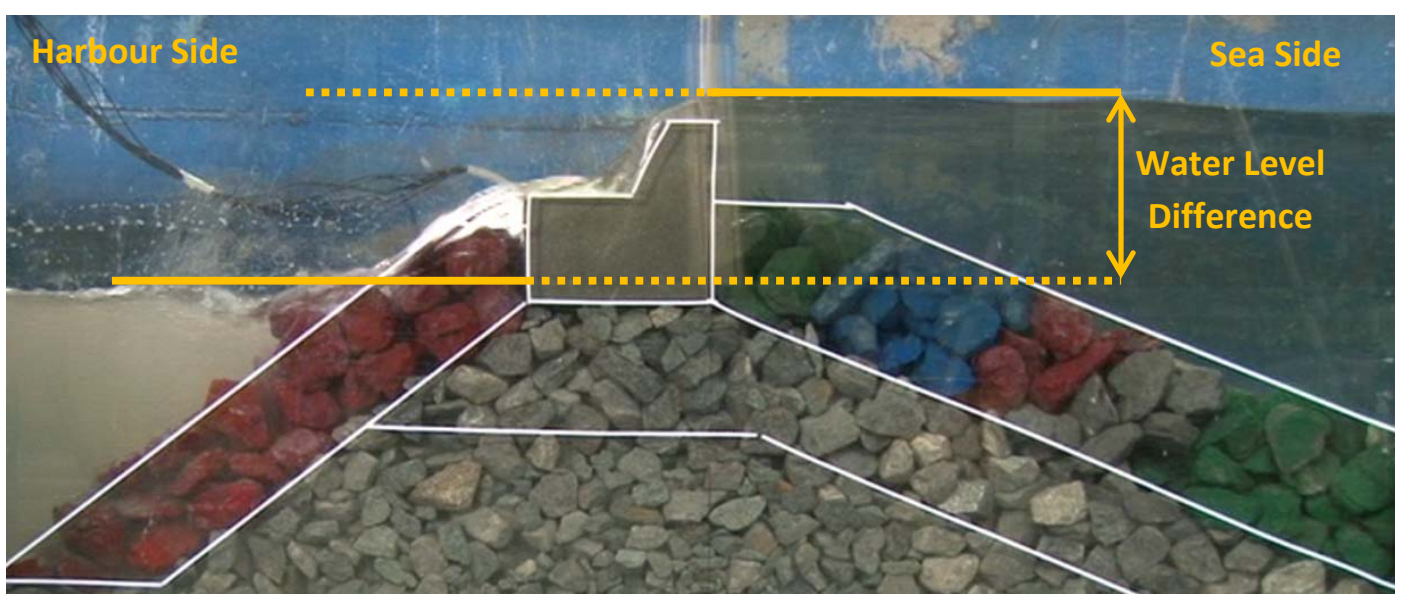

Figure 17: Water Level Difference between the Harbour and Sea Sides of the Cross-Section 
Driving forces acting on the crown wall units are pressure forces due to the water level difference. On the other hand, weight of the crown wall units and resisting forces due to the armour layer at the harbour side are the forces supporting the driving forces.

The resisting forces due to the armour layer at the harbour side decreased because of erosion and/or moving stones caused by solitary waves or tsunami overflow. Therefore, crown wall units slide. In Figure 18 , eroded region and moving stones are indicated.

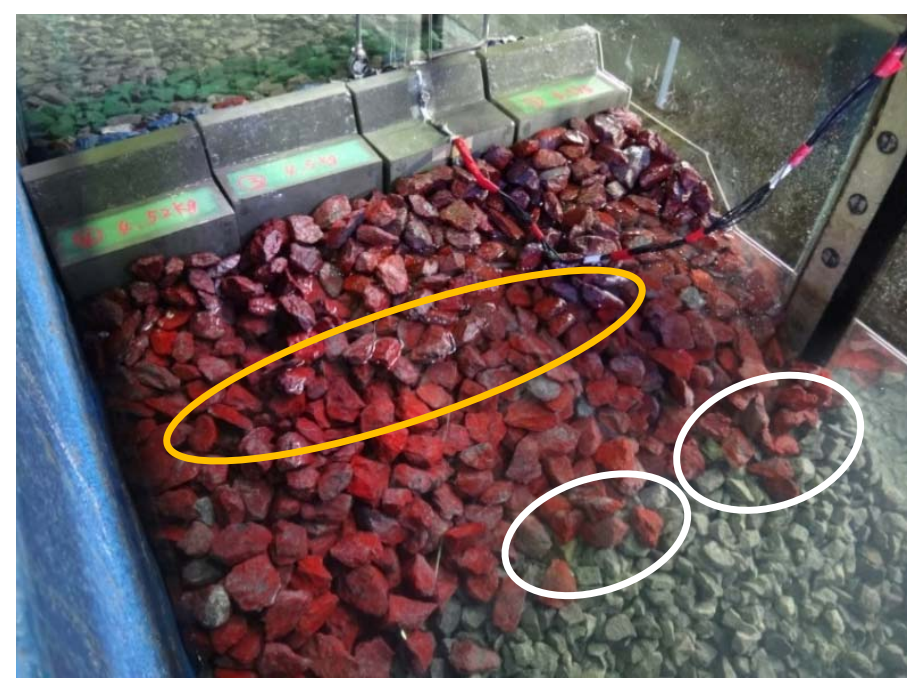

Figure 18: Eroded areas (yellow) and Moving Stones (white)at the Harbour Side

The stones are generally placed and oriented in the rubble mound breakwaters randomly. This randomness causes differences in engagement forces between stones. Throughout the physical model experiments, it is observed that engagement forces can change damage conditions or failure times. Tsunami overflow experiments on the original cross-section with an overflow height of $1.7 \mathrm{~cm}, 1.9 \mathrm{~cm}$, and $1.95 \mathrm{~cm}$ in model scale resulted in 'failure'. On the other hand, an overflow height of $1.85 \mathrm{~cm}$ on the original cross-section just caused 'small sliding'. Furthermore, $1.9 \mathrm{~cm}$ tsunami overflow height caused 'failure' in 6.5 minutes whereas $1.95 \mathrm{~cm}$ tsunami overflow height totally damaged the cross-section in 2 minutes and 10 seconds on the original cross-section. Similarly, an overflow height of $4.4 \mathrm{~cm}$ on the improved cross-section caused sliding of two out of the four crown wall units. These situations can probably be explained by the differences in engagement forces originating from randomness in placement and orientation of stones. In a similar manner, when the supporting forces increase due to orientation and placements of stones, failure time increases. The supporting forces given in Table 9 are also in the same direction with these comments. However, physical model experiments should be 
repeated several times under the same conditions to certainly conclude that these situations are originated from the randomness in placement and orientation of stones.

\subsection{Effect of Tsunami on the Armour Layer at the Sea Side Compared to the Armour Layer at the Harbour Side}

Rubble mound breakwaters are usually designed to stand extreme storm conditions. Wind waves have a cyclic motion, and that cyclic motion mainly affects the armour layer at the sea side. However, tsunami acting on Haydarpasa Breakwater does not affect the armour layer at the sea side as observed in both type of experiments. If crown wall units do not slide, no significant damage occurs in the armour layer at the sea side. On the other hand, if crown wall units slide, the upper parts of the armour layer at the sea side will wash away with crown wall units. However, the lower parts of the armour layer at the sea side may still be stable after a tsunami attack. Figure 19shows this kind of damage pattern. Moreover, several references maintain that the armour layer at these a side is mostly damaged by outgoing wave(Kato et al., 2012; Esteban et al., 2013).

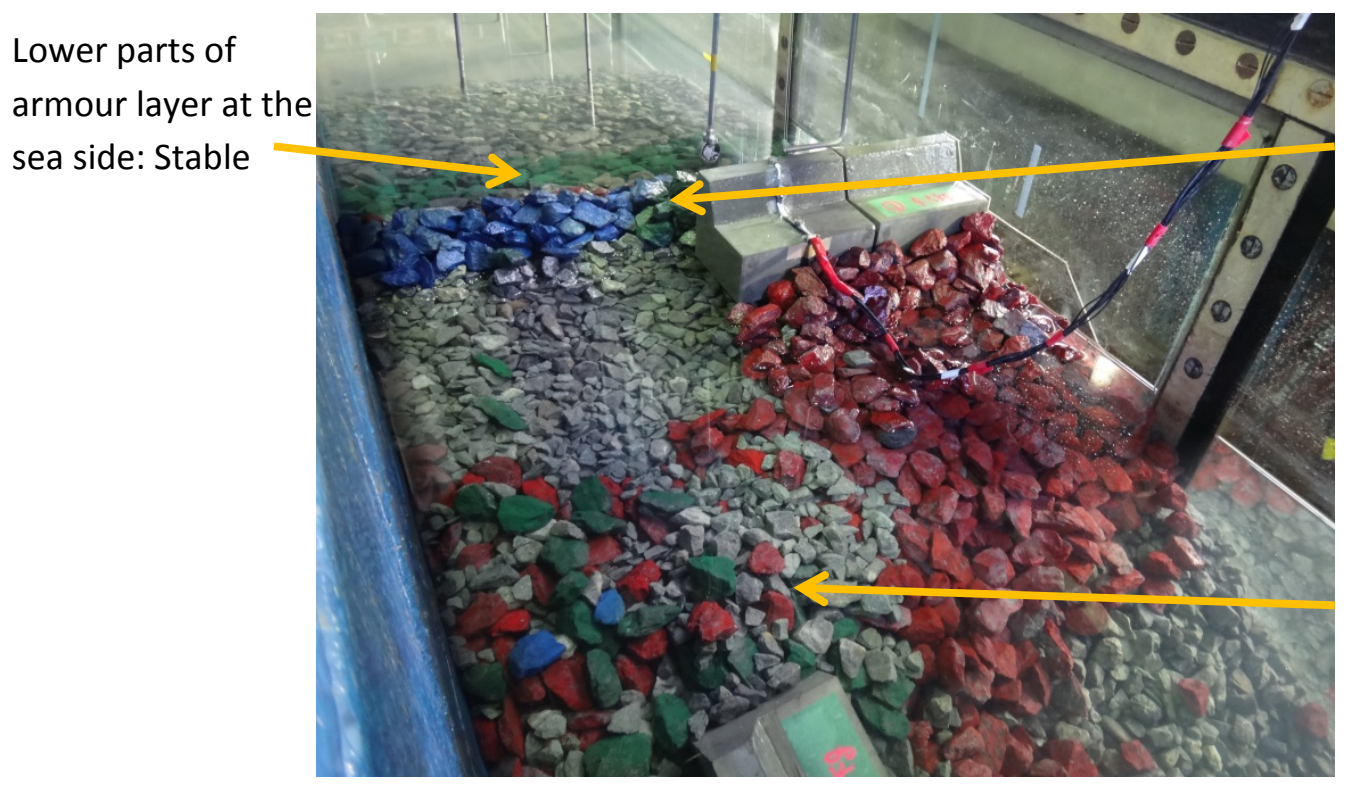

Upper parts of armour layer at the sea side: Stable if it is in front of nonsliding crown wall units

Upper parts of armour layer at the sea side: Washed away with sliding crown wall units

Figure 19:Damage Pattern of the Armour Layer at the Sea Side

\subsection{Evaluation of the Improved Cross-Section}

Experiments on the original cross-section of Haydarpasa Breakwater proved that this breakwater will not stable under a possible tsunami attack in that region. Therefore, a counter-measure was proposed and tested. Experiments on the improved cross-section showed that the armour layer at the harbour side can be enhanced by doubling the width of the armour layer so that the effect of tsunami can be 
effectively restrained. Considering the tsunami height of $3 \mathrm{~m}$ in prototype scale, which corresponds to $4.6 \mathrm{~cm}$ overflow height in model scale, a slight increase in the armour layer width of the improved crosssection would result in 'intermediate damage' under a possible tsunami attack. Furthermore, a comparison of supporting forces given for original and improved cross-sections in Table 9 shows that this improvement results in an around 10-15 times greater supporting force. This ensures that the proposed counter measure cross-section is not only effective but also economical. Other examples of counter measure cross-sections can be heavier crown wall units attained by increasing dimensions, higher weight of the armour layer and/or crown wall units, and deformable crown wall units.

\section{CONCLUSIONS}

Possible performance of the rubble mound breakwater of Haydarpasa Port in case of a tsunami attack is investigated by conducting physical model experiments. To understand the tsunami effect more clearly, the experiments were conducted in two parts. In the first part of the physical model experiments, solitary waves are used as the incoming wave. In the second part of the physical model experiments, the constant level overflow is used as the continuous flow by long period tsunami.

Previous results of numerical modelling studies revealed that there is a possibility of a 3 meter high tsunami in the region of Haydarpasa Port. Therefore, in the first part of the experiments, the heights of incoming solitary waves were chosen as $5 \mathrm{~cm}, 7.5 \mathrm{~cm}$, and $10 \mathrm{~cm}$ in model scale with a $1 / 30$ length scale as for the case studies. The solitary wave experiments showed that Haydarpasa Breakwater is stable under the action of $5 \mathrm{~cm}$ high solitary wave in model scale, whereas it suffers from 'initiation of damage' at the sea side under the effect of $7.5 \mathrm{~cm}$ high solitary wave in model scale. However, 'failure' occurs under the application of $10 \mathrm{~cm}$ high solitary wave in model scale.

Tsunami overflow experiments were the second part of the experiments where a variety of overflow heights were tested. The range of overflow heights were determined according to the results of solitary wave experiments that were conducted in between $1.1 \mathrm{~cm}$ and $4.6 \mathrm{~cm}$ model scale. The current crosssection of the Haydarpasa Breakwater failed in tsunami overflow height around $1.8 \mathrm{~cm}$ in model scale. Therefore, a counter measure cross-section was proposed and tested under stronger tsunami overflow heights. This counter-measure cross-section reacted much better and can be a comparatively economical solution to strengthen Haydarpasa Breakwater.

The series of experiments showed that the failure mechanism of Haydarpasa Breakwater under the attack of solitary like long waves is the sliding of crown wall units. It occurs mainly due to water level 
difference between the sea side and harbour side of the breakwater. In addition to the weight of crown wall units, resisting forces due to the armour layer at the harbour side is effective in resisting the driving forces. Engagement forces between stones differ for each experiment due to the randomness in placement of stones. This random placement causes difference in failure times.

Tsunami attack on Haydarpasa Breakwater does not cause significant effect on the armour layer at the sea side layer in the first hand. If there is 'no damage' or 'intermediate damage' at the harbour side of the breakwater; i.e. if the crown wall units do not slide, the armour layer at the sea side is mostly stable. However, if the crown wall units slide, upper parts of the armour layer at the sea side wash away with crown wall units. On the other hand, lower parts of the armour layer at the sea side are not affected from tsunami attack.

In conclusion, the performance of Haydarpasa Breakwater under the attack of solitary type long waves and continuous overflow during tsunami attack is investigated by physical model experiments. The results and discussions depend on the structural and hydraulic parameters used in the experiments. Further experiments with different types of rubble mound breakwaters under different types of wave and flow conditions are necessary for further generalization. Since the crown wall units slid certainly before the evolving damage in the armour layer at the harbour side, it is not possible to interpret results of these physical model experiments in terms of rear armour slope damage. Furthermore, it is observed that damage in the armour layer at the harbour side was lower when the crow wall units did not slide (Figure 15). To extend investigations on the rear armour slope damage and to understand the pressure forces on the crown wall units, physical model experiments are required with fixed crown wall units.

Acknowledgements: Support by Japan-Turkey joint Science and Technology Research Partnership for Sustainable Development (SATREPS) research project titled "Earthquake and Tsunami Disaster Mitigation in the Marmara Region and Disaster Education in Turkey" by Japan Science and Technology Agency (JST) is acknowledged. Furthermore, detailed reviews and comments of anonymous reviewers that increased the quality of this study are appreciated. 


\section{References}

Ahrens, J. P. (1975) "Large Wave Tank Tests of Riprap Stability", Coastal Engineering Research Center, Technical Memorandum No. 51, USA

Arikawa, T., Sato, M., Shimosako, K., Hasegawa, I., Yeom, Gyeong-Seon, Tomita, T. (2012) "Failure Mechanism of Kamaishi Breakwaters due to the Great East Japan Earthquake Tsunami", The International Conference on Coastal Engineering (ICCE) Proceedings 2012, COPRI, ASCE

Altinok, Y., Alpar, B., Ozer, N., Aykurt, H. (2011) "Revision of the Tsunami Catalogue affecting Turkish Coasts and Surrounding Regions", Natural Hazards and Earth System Sciences, 11, 273-291

Ayca, A. (2012) "Development of a Web GIS Tsunami Inundation Mapping Service: A Case Study of the Sea of Marmara Region", MSc Thesis, Department of Civil Engineering, METU, Ankara, Turkey

Aytore, B. (2015) "Investigation of Performance of Ports under Tsunami Attack by High Resolution Modeling", MSc Thesis, Department of Civil Engineering, METU, Ankara, Turkey

Broderick, L. L. (1984) "Riprap Stability versus Monochromatic and Irregular Waves", MSc. Thesis, George Washington University, USA

CIRIA, CUR and CETMEF(2007)“The Rock Manual:The use of Rock in Hydraulic Engineering", $2^{\text {nd }}$ Edition, C683, CIRIA, London

Estaban, M., Jayaratne, R., Miakmi, T., Shibayama, T., Mizuno, Y., Kinoshita, M., Matsuba, S. (2013) "Analysis of the Stability of Armour Units during the 2004 Indian Ocean and 2011 Tohoku Tsunami", Coasts, Marine Structures and Breakwaters, Institution of Civil Engineers Proceedings 2013

Etemad-Shahidi, A., Bonakdar, L. (2009) "Design of Rubble Mound Breakwater using M5 Machine Learning Method", Applied Ocean Research 31, 197-201.

Etemad-Shahidi, A., Bali, M. (2011) "Stability of Rubble Mound Breakwater using $H_{50}$ Wave Height Parameter", Coastal Engineering 59, 38-45, Elsevier, The Netherlands

Guler, H. G., Arikawa, T., Aytore, B., Tomita, T., Zaytsev, A., Yalciner, A. C. (2014) "High Performance Computing for Comparing Performance of 2D/3D Hybrid Tsunami Simulation Models: A Case Study in Haydarpasa Port in Istanbul, the Sea of Marmara", Asia Oceania Geosciences Society (AOGS) 2014, July 28- August 01, 2014, Sapporo, Japan

Hedar, P. A. (1960) "Stability of Rock-Fill Breakwaters", PhD Thesis, University of Goteborg, Sweden

Hudson, R. Y. (1959) "Laboratory Investigations of Rubble Mound Breakwaters", WES Report, Vicksburg, Mississippi, USA

Hydralab (2007) "Guidelines for Wave Modelling in Flumes and Basins: Hydraulic Model Testing in Waves", DHI, Denmark 
Kato, F., Suwa, Y., Watanabe, K., Hatogai, S. (2012) "Mechanisms of Coastal Dike Failure Induced by The Great East Japan Earthquake Tsunami", The International Conference on Coastal Engineering (ICCE) Proceedings 2012, COPRI, ASCE

Madsen, P. A., Fuhrman, D. R., Schaffer, H. A. (2008) "On the Solitary Wave Paradigm for Tsunamis", Journal of Geophysical Research, Vol. 113, C12012

Oyo Int. Co. (2011) "Simulation and Vulnerability Analysis of Tsunamis Affecting the Istanbul Coasts", Project Report in Micro Zonation Study for Istanbul supported by Istanbul Metropolitan Municipality, http://yalciner.ce.metu.edu.tr/marmara/index_eng.htm

Thompson, D. M. and Shuttler, R. M. (1976) "Design of Riprap Slope Protection Against Wind Waves", HRS, Wallingford, CIRIA Report No:61, UK

Van der Meer, J. W. (1988)"Rock slopes and gravel beaches under wave attack", Ph. D. Thesis, Delft University, The Netherlands

Vidal, C., Martin, F. L., Negro, V., Gironella, X., Madrigal, B., Garcia Palacios, J. (2003) "Measurement of Armour Damage on Rubble Mound Structures: Comparison between Different Methodologies", ASCE Coastal Structures 2003 Proceedings pp. 189-200, Portland, Oregon, USA.

Vidal, C., Medina, R., Lomonanco, P. (2006) "Wave Height Parameter for Damage Description of Rubble Mound Breakwater", Coastal Engineering 53, 712-722, Elsevier, The Netherlands

Yalciner, A. C., Alpar, B., Altinok, Y., Ozbay, I., Imamura, F. (2002) "Tsunamis in the Sea of Marmarahistorical documents for the past, models for the future", Marine Geology 190 (1-2), 445-463

Yalciner, A. C., Aytore, B., Guler, H. G., Kanoglu, U., Duzgun, S., Zaytsev, A., Arikawa, T., Tomita, T., Ozer Sozdinler, C., Necmioglu, O., Ozel, N. M. (2014) "High Resolution Tsunami Modeling and Assesment of Harbour Resilience: Case Study in Istanbul", European Geosciences Unioun (EGU) General Assembly 2014, April 27 - May 02, 2014, Vienna, Austria 